\title{
Collisions and Attention
}

\author{
Carol O'Sullivan* \\ Trinity College Dublin \\ Richard Lee \\ Trinity College Dublin
}

(a)

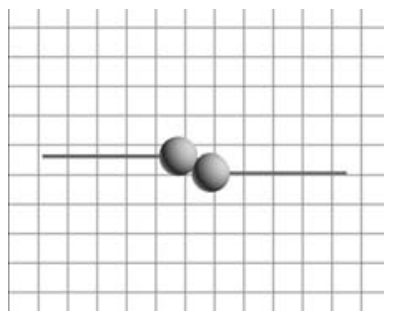

(b)

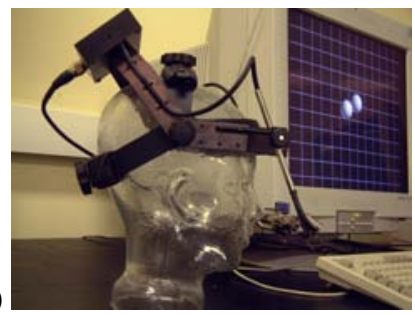

(c)

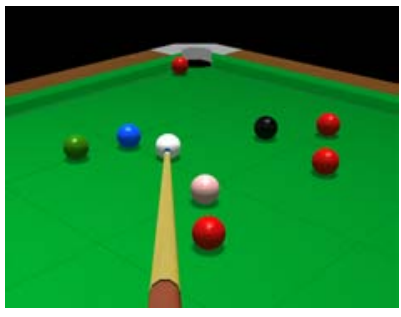

Figure 1: We ran a series of experiments to determine the source of biases in the perception of anomalous collision dynamics. In a paperbased experiment (a), participants were asked to sketch the predicted post-collision trajectories of two spheres; Using an eye-tracker (b), eye-movements were recorded while participants viewed animations of simple collision events. We are working on extending these studies to a more natural environment, such as a snooker game (c).

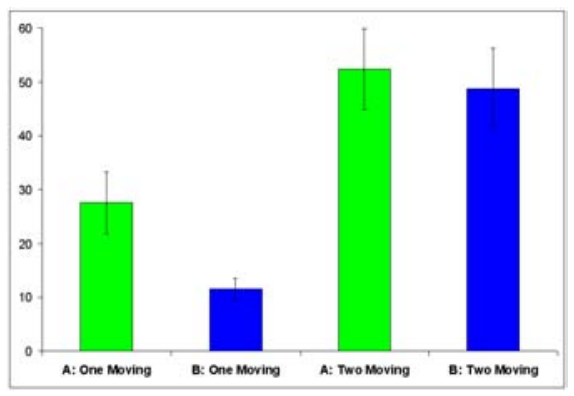

Figure 2: Paper-based experiments: the same biases as in O'Sullivan et al. were present in the one moving case $(F(1,26)=$ $6.1, p<0.02)$, but not when both balls were described as moving.

In O'Sullivan et al. [2003], participants viewed a series of simple collision events in which a stationary ball (B) was struck by a moving one (A). One interesting bias recorded was that distortions to A's post-collision trajectory were more acceptable than to B's. We postulated that this was due to the fact that participants were looking at ball B and not ball A. However, in this abstract we show that people also exhibited the same bias when asked to sketch the trajectories on paper (Figs. 2, 3), which appears to cast doubt on this theory. Also, eye-tracking data shows that most people actually looked at the striking ball more (Figs. 4, 6(a)). Unexpectedly, this was also the case for four participants in the new two-moving case (Fig. 5, 6(b)). However, this seems to be due to the fact that A only struck $\mathrm{B}$ on top in the latter case as illustrated by the results of a control experiment, where both angles were used on two participants (Fig. 5, rightmost image, Fig.6(c)). The top half of the display was also looked at more. Clearly, further investigation of the role of attention in the perception of dynamic anomalies is required.

\section{References}

O'Sullivan, C., Dingliana, J., Giang, T., \& Kaiser, M.K. 2003. Evaluating the visual fidelity of physically based animation. ACM Trans. Graph. 22, 3, 527-536.

\footnotetext{
*e-mail: Carol.OSullivan,Richard.Lee@cs.tcd.ie

Copyright $\odot 2004$ by the Association for Computing Machinery, Inc.

Permission to make digital or hard copies of part or all of this work for personal or classroom use is granted without fee provided that copies are not made or distributed for commercial advantage and that copies bear this notice and the full citation on the first page. Copyrights for components of this work owned by others than ACM must be honored. Abstracting with credit is permitted. To copy otherwise, to republish, to post on servers, or to redistribute to lists, requires prior specific permission and/or a fee Request permissions from Permissions Dept, ACM Inc., fax +1 (212) 869-0481 or e-mail permissions@acm.org.

(c) 2004 ACM 1-58113-914-4/04/0008 $\$ 5.00$
}

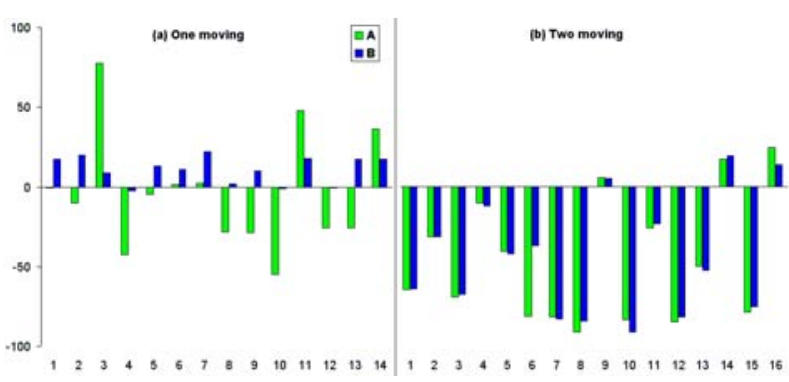

Figure 3: Paper-based experiments by participant: (a) people preferred expansion of B's trajectory but, as before, had no preference for A's direction; (b) when both balls were initially moving towards each other, people generally underestimated the angle of both balls.

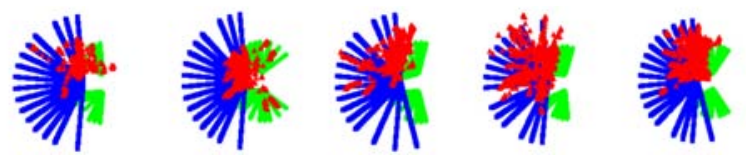

Figure 4: Eye fixations (in red) for animated one-moving experiments (5 participants): simulations as in O'Sullivan et al.

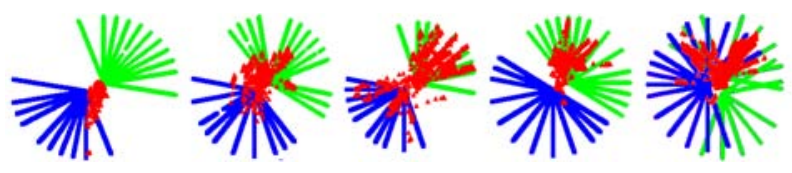

Figure 5: Eye fixations for animated two-moving experiments.

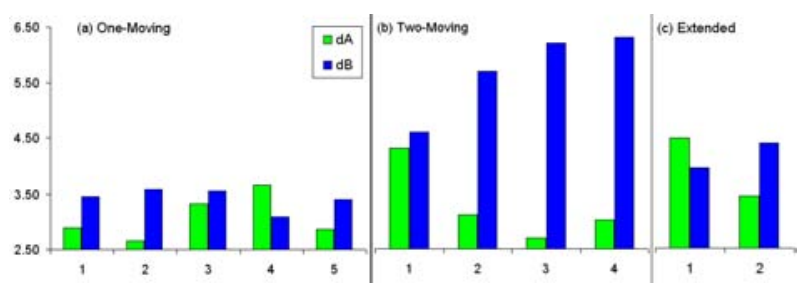

Figure 6: The average distances, per participant, to the centre of each ball. All results were highly significant $(p \approx 0)$. 